\title{
Sobre as Mulheres e o Aborto: notas sobre leis, medicina e práticas femininas
}

\author{
About Women and Abortion: notes on law, medicine and women's practices
}

\author{
Georgiane Garabely Heil Vazquez \\ Universidade Federal do Paraná - Brasil \\ profgeorgiane@hotmail.com
}

\begin{abstract}
Resumo
Este artigo tem o objetivo de debater sobre as práticas de aborto. Para isso foi utilizada uma abordagem histórica, procurando analisar o debate médico e o jurídico sobre tal prática entre os séculos XIX e meados do século XX. Visa-se analisar a vinculação estabelecida por diversos saberes, dentre eles o Jurídico e o médico, sobre o papel social da mulher e o exercício da maternidade. O artigo demonstra que o Poder Judiciário, assim como a medicina, desempenham papel central no que se refere aos desdobramentos das práticas de aborto feitas por mulheres. Em termos metodológicos foram utilizadas análises de discursos encontrados em documentação médica - teses- publicadas pelas Faculdades de Medicina no século XIX e início do XX, assim como análise de processos- crime ou inquéritos encontrados nas cidades de Castro e Ponta Grossa sobre aborto no mesmo período supracitado.
\end{abstract}

Palavras- Chave: Gênero; Aborto; Justiça; Medicina.

\begin{abstract}
This article aims to discuss the practice of abortion. For this, we used a historical approach, assessing the medical and legal debate about this matter between the nineteenth and the mid-twentieth centuries. We aim to analyze the linkage established by several knowledges, including the law and medicine, on the social role of women and the exercise of motherhood. The article demonstrates that the judiciary, as well as the medical practice, play a central role with regard to developments in the practice of abortion made by women. In methodological terms, we analyzed the discourses found in medical documentation - theses, published by Medicine faculties in the nineteenth and early twentieth centuries - , as well as criminal proceedings or investigations found in the cities of Ponta Grossa and Castro concerning abortion in the period mentioned above.
\end{abstract}

Keywords: Gender; Abortion; Justice; Medicine. 


\section{Notas Preliminares}

Todas as coisas são castas para os castos. A aprovação da minha consciência basta-me Jerônimo, To Eustochium (MCLAREN, 1990, p. 109).

Quatro de novembro de 2003, o Fórum da cidade de Castro, no interior do Paraná, estava muito movimentado, afinal havia chegado o dia do julgamento de Mary, uma mulher pobre que sabia fazer partos e também abortos. No ano de 2001, sua 'clínica clandestina' de aborto foi 'estourada' e ela permanecia presa, deste então, aguardando julgamento. Ao todo a promotoria conseguiu a comprovação de sete abortos e por estas práticas a parteira estava sendo julgada.

Um grande tumulto de advogados, funcionários do Fórum, policiais, repórteres e membros da comunidade estavam assistindo a um júri-espetáculo, onde se confrontavam as normas jurídicas com as práticas populares da eliminação de uma gravidez indesejada. A promotoria pedia a condenação por se tratar da morte de 'sete seres humanos inocentes', que nada podiam fazer para se defenderem de mães perturbadas e da parteira oportunista.

Já o advogado de defesa argumentou que o aborto 'é um problema muito mais social, de pobreza, de marginalização, de desespero, de falta de educação, em uma palavra, de ausência da atuação positiva do Estado'. Afirmou que em uma casa miserável uma criança a mais poderia significar uma tragédia. Assim, compôs a defesa afirmando que Mary apenas havia ajudado outras mulheres, pobres como ela, em um momento de desespero. Terminou a defesa perguntando para os jurados se: 'pode ser considerado crime, passível de punição, uma coisa que ainda não está resolvida em nossas cabeças?'

Concluído todo o ritual jurídico das falas de promotores, advogados e testemunhas, os jurados se dirigiram até a sala de votação. Em torno de 40 minutos depois a juíza leu a sentença que absolvia a ré em seis dos sete abortos. Foi condenada somente pela eliminação de uma das gestações no seu quarto mês, porém como já havia ficado presa em meados de 2001 até novembro de 2003 pôde sair livremente do Tribunal de Júri. Assim terminou mais um dos casos de aborto em que o Poder Judiciário interviu.

Este artigo analisa, em uma perspectiva histórica, os processos - crimes de aborto disponíveis nas comarcas de Castro e Ponta Grossa (PR) num período que compreende o fim do século XIX até meados do século XX. É necessário salientar que entre inquérito e processo o número total de casos de abortos registrados pelo Poder Judiciário é de apenas cinco casos. Tal número aponta para o fato de que práticas de impunidade são bastante comuns para os casos de abortamentos, pois se acredita que o número de abortos acorridos nas cidades de Castro e Ponta Grossa (PR) entre o século XIX e meados do século XX foi superior a cinco. Todavia, ficaram registrados nos arquivos do Poder Judiciário apenas cinco casos.

Segundo o levantamento feito desses casos, quando estes chegam ao Poder Judiciário trazem à tona mulheres pobres e geralmente solteiras. Porém, a pena de prisão para mulheres que abortam é rara. E esta sempre foi uma das questões centrais para a discussão do aborto nos meandros da justiça brasileira. Como um discurso jurídico tão repressor gerava cenas como aquela ocorrida em Castro-PR no final de 2003? Por que as sentenças eram, na maioria das vezes, de absolvição.

Embora seja uma prática antiga, é nos séculos XIX e XX que ocorreu a 'generalização do aborto' e sua extensão massiva a todas as camadas sociais. De acordo com Nacur e Valent (2003) a passagem de uma sociedade tradicional para uma sociedade industrial, o afrouxamento da tutela religiosa sobre os costumes e os 
indivíduos, a urbanização e as condições materiais da civilização capitalista vieram justificar e facilitar as práticas de aborto. Foi ao longo do século $\mathrm{XX}$, que se verificou, paulatinamente, uma modificação dos métodos e das técnicas abortivas, onde as velhas poções tradicionais de ervas e chás cederam progressivamente diante de abortos por meios mecânicos e com uso de medicamentos farmacológicos e das sondas intrauterinas.

Nacur e Valent (2003) salienta que o aborto foi crime contra a autoridade marital ou paternal na Antiguidade, depois, no medievo, contra Deus e a moral. Posteriormente a recusa feminina à maternidade se transformou num ato contrário aos interesses da sociedade e do Estado a partir do período contemporâneo. Seria necessário que as mulheres tivessem filhos, com vistas ao futuro do país e, neste sentido, a eliminação de gestações ou de crianças passou a ser considerada ameaça à nação.

$\mathrm{O}$ tema analisado neste artigo se refere a uma experiência singular na vida afetivasexual de inúmeras mulheres brasileiras. Todavia, o aborto e o debate que o cerca não é, na maioria das vezes, tratado com a abordagem merecida, ou seja, como uma questão de saúde pública e de parte importante dos direitos femininos.

Por meio dos autos criminais dos séculos XIX e meados do século XX existentes nas cidades de Castro e Ponta Grossa (PR), analisamos os discursos e representações sobre as mulheres envolvidas nas práticas de aborto, assim como as próprias práticas femininas para se livrar de um filho indesejado. Este artigo tem como eixo norteador uma análise histórica das práticas de aborto assim como de juristas e médicos que se propuseram a debater sobre este assunto em seus tratados.

Porém, mais do que evidenciar os discursos sobre a maternidade e o aborto, a transformação desses atos femininos em autos penais revelou o caráter público destes acontecimentos e permitiu que tais vivências chegassem até nós. Os processos-crime são fragmentos de histórias de vidas, um tipo específico de história que permaneceu marginal durante muito tempo na academia, tanto pelo tema que se propunha a analisar quanto pelos sujeitos sociais com que trabalhava. Esse tipo de documentação é, com certeza, um dos poucos caminhos de acesso às vidas e às sociabilidades dos populares no passado e também do presente.

Assim, em termos metodológicos, este artigo discute o aborto historicamente e, para tanto, foi recorrido a uma literatura médica e jurídica de épocas passadas (século XIX e XX) para se debater sobre este tema. Com a análise de doutrinas jurídicas e de teses médicas publicadas até a primeira metade do século $\mathrm{XX}$ acredita-se poder apresentar, ao menos de forma parcial, uma relevante discussão sobre um problema sociocultural que infelizmente ainda mata muitas brasileiras anualmente.

\section{Breve Análise Histórica da Legislação sobre o Aborto}

A lei escrita pedirá contas a essa mulher, como
autora de um crime, mas a lei moral dirá a seus
juízes: acima e além dos códigos há a lei da
necessidade [...] o império inelutável das fatais
contingências da vida. (Nelson Hungria.
Comentários ao Código Penal).

Nessa parte objetiva-se discutir acerca dos discursos e normas jurídicas sobre aborto utilizando para isso o Código Criminal do Império do Brasil de 1830, o Código de 1890, e uma breve análise do de 1940.

Sabemos que os métodos abortivos e as práticas de infanticídio são ações femininas recorrentes ao longo da história. As mulheres de Ponta Grossa e Castro (PR), como as de outras regiões do Brasil, possuíam conhecimentos adequados para a eliminação 
de uma gestação ou de uma criança quando julgassem necessário (PEDRO, 2003). Esses conhecimentos, possivelmente com modificações, permanecem vivos e ainda são temas de conversas femininas. São saberes que funcionam como uma espécie de proteção, caso as mulheres se vejam lançadas em situações de gravidez indesejada e não planejada.

Porém, embora de certa forma sendo práticas conhecidas e, recorrente entre mulheres de vários níveis sociais, os saberes jurídicos classificaram esses atos femininos como crime. Assim, as mulheres denunciadas tiveram seus corpos vasculhados por médicos e sua moral questionada pelo Poder Judiciário, sendo que este ainda ameaçava com a prisão as envolvidas diretamente nessas histórias.

Essa espécie de perseguição pode ser melhor compreendida quando observamos os diferentes Códigos Penais que já vigoraram no Brasil. É interessante mencionar o fato de que no primeiro código, redigido na primeira metade do século XIX, mais precisamente em 1830, não encontramos punição para a mulher que, estando grávida, desejasse o aborto. Nada consta de pena para a gestante que decidisse abortar. O Código de 1830 somente prevê punição para quem ocasionasse $\mathrm{o}$ aborto na gestante:

\footnotetext{
Secção III - Aborto

Art.199. Occasionar aborto por qualquer meio empregado interior ou exteriormente com consentimento da mulher pejada.

Penas - de prisão com trabalho por um a cinco annos. Se o crime for cometido sem o consentimento da mulher pejada - Pena dobrada

Art. 200. Fornecer com conhecimento de causa drogas ou quaisquer meio para produzir o aborto, ainda que este não se verifique.

Pena - de prisão com trabalho por dous
}

a seis annos. Se o crime for cometido por médico, boticário, cirurgião ou praticante de taes artes - Pena dobrada ${ }^{1}$. (BRASIL, 1830)

Verificamos que na primeira metade do século XIX o Direito não estava preocupado em responsabilizar a mulher pela interrupção da gravidez. Neste sentido, somente 'os cúmplices' do aborto estariam sujeitos aos rigores da lei. Com destaque para o fato de que sendo médico ou pessoa de algum 'conhecimento erudito' sobre o corpo feminino a pena seria dobrada. Isto seria uma forma de intimidar os doutores a praticarem o aborto. Outro ponto que a lei de 1830 não aborda é o autoaborto. Novamente demonstrado que para a gestante, em qualquer hipótese, o Código não previa pena. Assim, a legislação brasileira no início do XIX, se mostrava omissa com as mulheres gestantes que interrompiam a gravidez.

Nesta breve análise, deste diploma legal brasileiro, verificamos que cai por terra a ideia conservadora de que em tempos antigos o rigor penal era maior para as mulheres em qualquer situação.

Assim, a mulher que praticava um aborto, a mãe do feto, era poupada dos rigores legais e muitas vezes descrita ao longo do processo criminal como uma pobre coitada que em um momento de desespero teve que eliminar a gestação. Nos casos encontrados em Castro e Ponta Grossa (PR) que fazem referência a este período percebemos que as justificativas giravam em torno da pobreza extrema e ou do abandono do pai da criança. Assim, sozinhas e sem condições materiais, optavam pelo crime.

Com relação à prática de aborto, o Código de 1890, também trouxe novidades. A principal delas foi a punição para a gestantes envolvidas nesta prática. O Código menciona explicitamente a gestante e, a partir da publicação deste diploma legal elas também passaram a ser criminalizadas pela 
interrupção da gravidez. No caso do aborto o Código subdivide a prática em vários tipos e novamente com distinção de pena entre elas. Vejamos como a legislação tratou a prática do aborto no Brasil entre 1890 até 1940 (data da promulgação do novo Código Penal que ainda está em vigor):

Art. 300- Provocar aborto, haja ou não a expulsão do fruto da concepção:

No primeiro caso: - pena de prisão cellular por dous a seis annos.

No segundo caso: - pena de prisão cellular por seis mezes a um anno."

$\S 1^{\circ}$ - Si em conseqüência do aborto ou dos meos empregados para provocal-o, seguir a morte da mulher:

Pena: - de prisão celular de seis a vinte e quatro annos.

$\S 2^{\circ}-\mathrm{Si}$ o aborto for provocado por médico, ou parteira legalmente habilitada para o exercício da medicina:

Pena: - a mesma precedentemente estabelecida, e a de privação do exercício da profissão por tempo igual ao da condenação.

Art.301- Provocar aborto com annuencia e accordo da gestante:

Pena: de prisão cellular de um a cinco annos.

§único: - Em igual pena incorrerá a gestante que conseguir abortar voluntariamente, empregando para esse fim os meios; e com reducção da terça parte, si o crime for commetido para ocultar a deshonra própria. (grifo nosso).

Art. 302- Si o médico ou parteira, praticando o aborto legal, ou aborto necessário, para salvar a gestante da morte inevitável, accasionar-lhe a morte por imperícia ou negligencia:

Pena: - de prisão cellular por dous meses, e privação do exercício da profissão por igual tempo ao da condemnação. (BRASIL, 1890)

Observamos pela comparação entre os Códigos Penais de 1830 e 1890, que houve uma maior preocupação no final do século XIX com a punição da prática do aborto. Além disso, o Código de 1890 trouxe de maneira mais detalhada as possíveis situações envolvendo determinado grupo de pessoas junto ao aborto. Porém, a maior alteração se deu no artigo 301 parágrafo único deste código, quando também criminaliza as gestantes. A partir desse momento a prática do aborto passou a ser considerada um ato delituoso pela legislação brasileira, mesmo quando cometido pela gestante sozinha.

Essa mudança drástica na lei não afetou de imediato as práticas das mulheres. Pelo contrário, ela sofreu um processo de apropriação bastante lento por parte das gestantes que se encontravam diante de uma gravidez indesejada ou não planejada. (PEDRO, 2003). As mulheres envolvidas em situações como estas encontravam no aborto (de certa forma legal até 1890) uma possível solução para seu problema. Era uma forma de resguardar sua honra e por extensão, a de seus familiares. Ao criminalizar essa prática, mesmo quando envolvia exclusivamente a gestante, o judiciário lançou à margem da legislação todo um conjunto de saberes femininos que tratavam das lidas com uma gravidez indesejada. Além disso, juristas como Nelson Hungria (1956) apontam o fato de que a criminalização iniciada no Brasil com o Código de 1890 e mantida pelo Código Penal de 1940 não foi suficiente para inibir as mulheres de praticarem o aborto.

Com relação ao Código de 1940 e que é mantido ainda hoje no Brasil, observamos a manutenção da pena para a gestante. Porém as penas maiores são destinadas aos médicos, parteiras ou curiosos que auxiliam na prática abortiva.

Fato de destaque no código de 1940 é a possibilidade do dito 'aborto legal', nos casos em que houver comprovadamente risco de vida para a mãe ou a gestação for resultado de um estupro. 


\section{Aborto: Histórias Perdidas no Tempo}

A palavra aborto, na nossa cultura, é carregada de ideia preconcebida, impregnada de tabus e vergonhas. Era e é uma palavra que acusa as mulheres de se desviarem de seu 'destino biológico', de não levarem a cabo uma missão feminina. Na linguagem médica o termo correto é abortamento que significa, em uma definição obstétrica, a perda de uma gravidez antes que o embrião, ou posteriormente o feto, seja potencialmente capaz de vida independente da mãe. Deste modo, clinicamente é caracterizado como abortamento a interrupção voluntária ou não da gestação durante os seis primeiros meses.

Segundo Prado (1985) o diagnóstico dos tipos de abortos é complexo, haja vista que o útero elimina em torno de $15 \%$ dos óvulos fecundados sem que a mulher o perceba. Um pequeno atraso menstrual seguido de uma perda um pouco maior de sangue podem caracterizar um aborto espontâneo e algumas mulheres nem tomam conhecimento destas alterações em seu ciclo menstrual. Deste modo, muitos abortos naturais ocorrem e as mulheres jamais saberão que passaram por isso. Outra dificuldade, em se tratando da constatação e definição dos tipos de abortos, é o desejo da mulher em esconder a prática intencional de tal ato. Muitas, descobrindo-se grávidas, provocam acidentes e tombos, na tentativa de eliminar a gestação sem deixar culpa.

É difícil estabelecer com certeza as causas que levavam ao aborto, assim como a quase impossibilidade médica de distinguir entre um aborto criminoso ou natural, ao encontro disto temos a impossibilidade de deliberar se um tombo foi planejado ou acidental. Existe, portanto, uma tênue distância entre a vontade e o imprevisto, entre a ação inconsciente e a deliberada, entre a gravidez e o fato de não a ter desejado naquele momento. Destarte, o aborto é revestido de silêncio, é um terreno fluido e escorregadio mesmo para os médicos e agentes da justiça que 'vasculham' corpo feminino em busca das provas do crime ou do acidente.

$\mathrm{O}$ fato de não querer ter filhos causava ou ainda causa - espanto em determinadas sociedades e, mais especificamente, a mulher que recusa uma gravidez depois dela já estar concretizada era para muitas culturas um ato de monstruosidade e perversão sexual. Porém, deste o início do século $\mathrm{XX}$, os médicos e as Faculdades de Medicina encampam uma defesa do aborto necessário, ou seja, quando existe a necessidade de eliminar o produto da concepção para salvar a vida materna.

Existe uma certa homogeneidade no discurso médico em se tratando desse 'aborto terapêutico', pois as teses consultadas apontam para uma unanimidade em tratar-se de uma gravidez de risco, sendo dever dos médicos salvar a vida da mulher em prejuízo da vida fetal. Todavia, essa intervenção na gestação deveria ser feita com cuidado e somente por médicos devidamente qualificados. Defende-se, nas teses médicas, que somente os doutores teriam técnicas e autoridade moral para decidir e realizar um aborto necessário, e que em qualquer outra situação o recurso ao aborto deveria ser prontamente condenado pelos médicos. Deste modo, a medicina buscava paulatinamente tirar das parteiras e curiosas o direito de intervir na gravidez e no parto. Somente o médico teria essa autoridade e esse dever, sendo que para a realização de um aborto terapêutico era conveniente o parecer de mais de um médico para que fosse evitado o ceifar de uma vida inocente (o embrião ou feto) desnecessariamente.

$\mathrm{Na}$ França, alguns médicos reconheciam deste o início do século XIX a necessidade de que em alguns casos deveriam provocar o aborto para evitar sofrimentos ou até mesmo a morte de mulheres. Entretanto, essa foi uma 
discussão longa para a sociedade francesa e mesmo para os profissionais da medicina daquele país. Só o tempo e a experiência fizeram que os médicos franceses reconhecessem a necessidade desta operação, em certos casos, e que a pusessem em prática, logo que para isso se apresentasse uma indicação legítima. (MORAES, 1873).

$O$ debate acerca da necessidade médica de provocar aborto em determinados casos levou a Academia de Medicina de Paris em 1852 a analisar um caso em que vários médicos franceses, em diferentes anos, tiveram que provocar aborto em uma mesma jovem. Era a escolha entre a vida do feto ou da mulher, preferindo-se a segunda. A Academia de Medicina Francesa então nomeou uma comissão de médicos para dar um parecer sobre o chamado aborto necessário. Os médicos que já haviam praticado o aborto para salvar as mães argumentavam:

era útil que a Academia se pronunciasse a favor da operação, e este parecer da Academia, pela alta posição, e autoridade incontestável de que goza esta sábia corporação, serviria de norma para o futuro, de regra absoluta para sempre. (MORAES, 1873, p. x).

Então a comissão médica francesa, nomeada pela Academia, elaborou um relatório que se mostrou favorável ao aborto necessário/ terapêutico. Embora com algumas resistências, mesmo no meio médico, o aborto necessário passou a ser praticado na França. Os opositores temiam que essa prática aparentemente adequada acabasse servindo de refúgio para algumas mulheres que deliberadamente quisessem interromper a gravidez, gerando, segundo alguns médicos franceses, abusos femininos contra a maternidade.

No Brasil, a comunidade médica concordou que o aborto necessário deveria ser visto como um recurso médico para salvar vidas femininas. "O médico que provoca aborto, quando necessário e legítimo, não tem que temer os remorsos, nem 0 arrependimento". (MORAES, 1873, p 56). Muitos médicos, para realizarem abortos necessários, expunham as mulheres a situações apavorantes, como por exemplo, o uso da eletricidade para eliminar o feto por meio de contrações uterinas pondo um dos polos de uma pilha de Volta em contato com o fundo do útero e o outro com a porção vaginal. Todavia, felizmente a maior parte dos médicos brasileiros considerou este processo muito doloroso e em alguns casos ineficaz, abandonando-o.

Outra prática médica criada para a realização do aborto terapêutico foi $o$ processo de deslocamento da membrana. Essa manobra abortiva deveria ser realizada somente por um médico e consistia em forçar o colo do útero grávido com o dedo, assim transpondo o orifício interno e deslocando as membranas uterinas na maior extensão possível. Outro método semelhante para a realização de abortos por médicos era a chamada 'perfuração das membranas', essa prática obstétrica consistia em:

colocar a mulher em pé, ou em posição para a versão, o parteiro leva o dedo indicador e o médio da mão esquerda até á parte posterior do collo do útero, fixa-o, e, se for necessário, o conduz para adiante; é então que, sobre os dedos, elle dirige o instrumento perfurante, e com este penetra o orifício externo do collo uterino, sua cavidade, chega até ás membranas e as perfura. (MORAES, 1873, p. 60).

Muitas foram as tentativas $\mathrm{e}$ as metodologias empregadas pelos clínicos brasileiros ou de outras nacionalidades na tentativa de, em se tratando de uma gravidez de risco, salvar a vida das mulheres. Contudo, em alguns casos este processo se mostrou 
traumático e doloroso, mas ao menos confirmou a intenção e o posicionamento dos médicos brasileiros em se alinharem com a Academia de Medicina da França, e assim realizarem livremente o aborto terapêutico quando a morte da mulher poderia ser eminente.

Uma outra categoria de aborto analisada pelos médicos nas teses diz respeito a interrupção acidental ou natural da gestação. Muitos médicos dedicam espaço em seu trabalho de conclusão de curso para o chamado 'aborto acidental'. Entre as causas de interrupção traumática da gravidez por acidente foram destacados os choques diretos sobre o útero tais como: quedas, saltos, corridas, caminhadas excessivas, passeios de automóveis ou mesmo de trem, sendo que os de automóveis não deveriam ser longos nem frequentes, de maneira a evitar o balanço e a velocidade. (FERREIRA, 1907). Nesta linha, os médicos acreditavam que as grávidas teriam que zelar de sua situação para evitar os abortos e qualquer sobressalto. Além disso, a dança e a natação não eram recomendadas para as gestantes, do mesmo modo que as cavalgadas seriam muito prejudiciais ao feto, não só pela má posição em que se achava a mulher para cavalgar como também pelos desastres de possíveis quedas.

O corpo feminino era visto pelos médicos durante a gravidez como um casulo destinado a abrigar de maneira sadia uma nova vida. Durante a gestação a mulher deveria apenas repousar para evitar contratempos enquanto aguardava a vinda da criança. A cauterização do colo do útero, o cateterismo uterino, ou mesmo as relações sexuais violentas ou praticadas seguidamente deveriam ser evitadas durante a gestação para que a vida do feto não corresse risco.

Foi possível verificar ainda um arrolamento de outras causas que, segundo os médicos, seriam potenciais geradoras de abortos. Entre esta listagem temos o conselho de que toda mulher grávida deveria subtrairse das coisas que produzissem fadiga excessiva. Deveria também evitar as emoções fortes, bem como os traumatismos e quedas. Além disso, era recomendado que abandonasse a sua profissão como um sacrifício em prol da maternidade, devendo também evitar longas caminhadas, exercícios prolongados e jamais usar espartilho ou qualquer outra vestimenta apertada durante a gravidez. Deveria igualmente fugir de moléstias infecciosas e ter redobrada cautela com a higiene. (CUNHA, 1905). Somente tomando todas essas precauções os abortos conseguiriam ser evitados e a mulher cumpriria seu dever. Dentro dessa perspectiva, acreditamos que os médicos buscaram maneiras de controlar o processo da gravidez e para isso criaram uma espécie de regulamento no qual constam todas as obrigações de uma gestante. Se mesmo seguindo as recomendações o aborto ocorresse, então seria uma fatalidade ou um descuido feminino, jamais a culpa recairia sobre a medicina.

Este tipo de receituário para as gestantes era bastante recorrente nas teses do início do século XX, pois acreditava-se que a ignorância materna poderia comprometer $\mathrm{o}$ bom andamento da gravidez ou mesmo produzir filhos com problemas para a sociedade. O Dr. Odetto de Carvalho redigiu uma tese intitulada: "A ignorância materna e a condição do nascituro", na qual organiza as informações que obteve durante o seu trabalho quando interno na Pró-Matre ${ }^{2}$ do Rio de Janeiro (RJ) para comprovar que mães pobres e analfabetas produzem 'crianças inferiores':

As analphabetas - as mães da ignorância - são as que por ordem natural das cousas e pela lógica de suas condições, estavam, estão e estarão, para todo o sempre, fadadas a contribuir com uma cifra maior de filhos 
physiologicamente indesejáveis (...).

Protejer a mulher grávida desamparada é dever das autoridades constituídas; e protejel-a é reverter em benefício da Nação a opulência de filhos fortes e sadios. (...)

A instrução traz a hygiene e a hygiene da grávida é indispensável ao nascituro como o pão á vida (sic). (CARVALHO, 1926, p 34).

precisavam mais dos cuidados e orientações dos médicos, pois devido à 'ignorância', estas mulheres não poderiam gerar bons filhos, conforme demonstrado pela figura 1 .

Percebemos então que nos casos de abortos ou mesmo em casos de crianças com problemas físicos e mentais a medicina responsabilizava a mulher e, em especial, a mulher pobre e negra. Este grupo feminino esteve mais propenso a cair nas tramas de acusação dos médicos

Ressaltando $\mathrm{o}$ aspecto reprodutor que o discurso médico confere às mulheres, Odetto de Carvalho afirmou que as "mães analphabetas concorrem com uma porcentagem de fetos inferiores sensivelmente superior às alphabetisadas" (sic). (CARVALHO, 1926, $\mathrm{p}$ 33). Para este médico a pobreza e mesmo a cor da pele da mãe poderia influenciar na má formação dos bebês. Ao longo de sua tese ele analisa vários fatores que poderiam influenciar na 'geração de crianças inferiores'. Um dos elementos destacados pelo

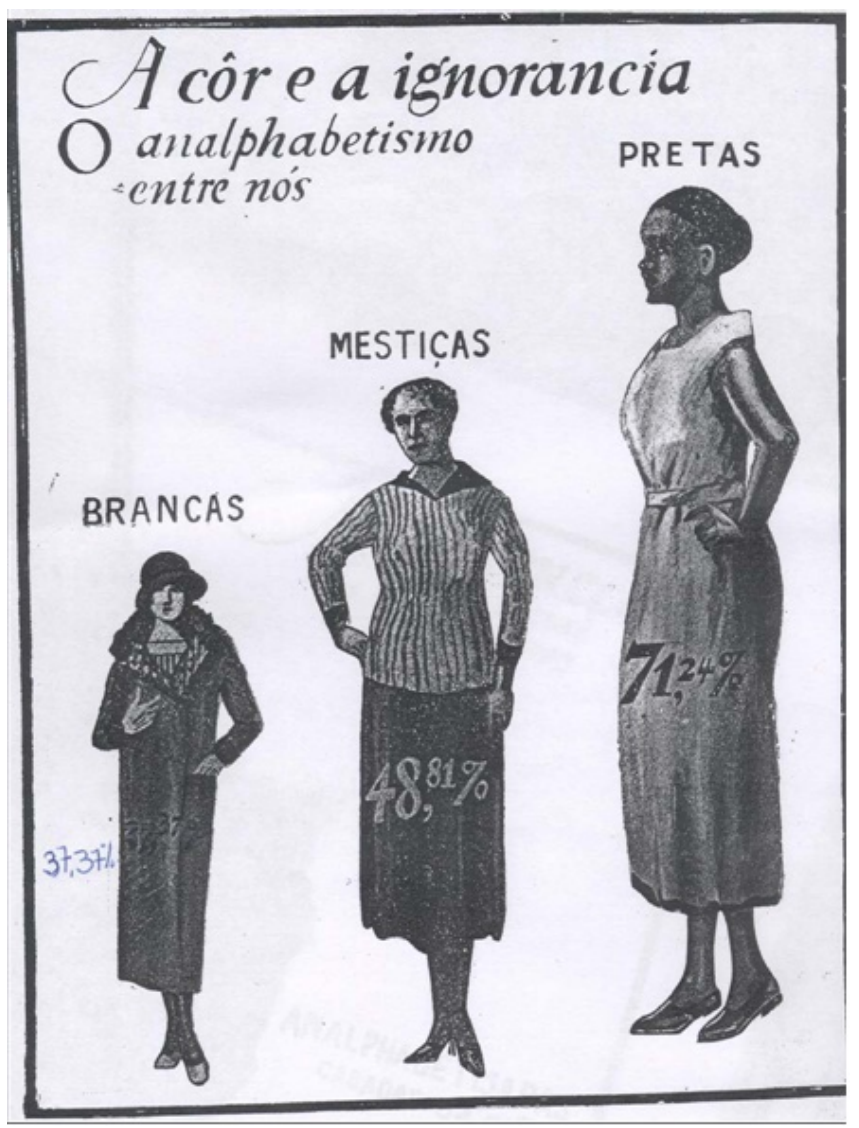

Figura 1: Gestantes da Pró-Matre divididas em grupos pela cor da pele e a instrução. Década de 1920. médico é a raça dasparturientes internadas na Pró-Matre. Na tentativa de traçar um perfil das mulheres que davam entrada nessa maternidade, o autor apresentou um gráfico confeccionado com os dados da referida maternidade relacionando a cor da pele e a instrução feminina, na tentativa de demonstrar que as negras e analfabetas e juristas nos casos de abortos espontâneos, mas principalmente nos episódios do chamado 'aborto criminoso'.

As teses médicas tentaram construir uma representação deste 'feminino delinquente', procurando analisar e investigar as mulheres que não estando loucas ou doentes, se submeteram ao aborto, caracterizando assim um delito feminino.Dr.

Fernando de .Magalhães dedica um capítulo de seu livro "Obstetrícia Forense" para a investigação e análise do chamado aborto criminoso. O capítulo tem início com uma condenação do médico aos homens, pois para ele, devido à perversidade masculina a mulher se sente explorada e desamparada, procurando compensar sua dor eliminando o fruto da ilusão amorosa: "o aborto é o recurso da mãe solteira e da mãe adultera: delito do desespero e do abandono, 
que não deve ser justificado, mas pode ser compreendido." (MAGALHÃES, 1925p 24). Entretanto, o autor aborda os casos de abortos dentro de 'uniões legítimas', ou seja, dentro do casamento, e afirma que esta prática é uma colaboração criminosa e premeditada contra as leis da natureza e da sociedade. Para ele o casal, depois da fecundação já efetuada, não teria o direito de dispor da opção de interromper a gestação; os fatores de ordem econômica como a pobreza ou a miséria não são abordados, sendo somente levantado o argumento moral do dever do casal e principalmente da mulher, de procriar.

Seguindo na condenação do aborto intencional o médico pontua três causas para o crime contra a 'vida embrionária' que seriam a sedução mentirosa e nesta atribui parte da culpa também aos homens pelos abortos frequentes das mulheres; o descrédito social e neste ponto acreditamos que cobra do Estado o papel de amparar as mulheres pobres; e por último o egoísmo sem freio, aqui insinuando que as mulheres, para se livrarem de suas obrigações maternais e querendo usufruir livremente de sua sexualidade, acabavam por realizar abortos de maneira deliberada e sem ressentimentos.

Argumenta ainda que os abortadores se dividem em duas grandes categorias: os inferiores e os de primeira classe. Compunha o primeiro grupo as parteiras e as 'curiosas', que além de utilizarem diuréticos e plantas para provocar o aborto, estavam também manipulando substância tóxicas como o aloés e o iodo, além de outras substâncias como as ervas de sabida, arruda e o centeio em proporções venenosas. Para alcançarem o êxito na eliminação do feto as mulheres se submetiam às mais variadas experiências, dentre elas a ingestão de purgativos e chás com fama de abortivos. A arruda e particularmente a sabina eram ervas procuradas para este fim, porém poucas vezes as mulheres conseguiam o resultado desejado pois as ervas não produziam o aborto, mas sim uma dosagem tóxica delas seria capaz de proporcionar um estado de 'envenenamento' no organismo feminino e, em decorrência deste, se iniciaria o aborto. Outra erva comumente mencionada nas tentativas domésticas de aborto era o centeio, todavia segundo os médicos, esta erva teria um poder muito pequeno de provocar as tão desejadas contrações uterinas. Ainda tratando das experiências a que se submetiam as mulheres na tentativa de abortar, encontramos nas teses relatos de gestantes que aplicaram sanguessugas à vulva, por acreditarem que assim teriam uma 'ação mais direta' do que a tradicional aplicação de sanguessuga no pé para conseguir eliminar a gestação. (MAGALHÃES, 1925).

Porém, segundo Fernando de Magalhães, havia um segundo agrupamento de pessoas que também se dedicavam ao aborto criminoso. Neste grupo denominado pelo médico de 'abortadores de primeira classe' encontram-se as pessoas que interrompem a gravidez de maneira cirúrgica e que geralmente com a ajuda de médicos conseguem a dilatação do útero e efetuam a curetagem, o que segundo Magalhães parecia ser um 'método mais limpo' (higiênico). Neste sentido, acreditamos que de acordo com as ideias higienistas do início do século $\mathrm{XX}$, Fernando de Magalhães condenava o aborto, mas reconhecia que somente um médico teria a capacidade de intervir e interromper uma gestação, mesmo que de forma criminosa. Contudo, foi veemente na condenação de colegas que ajudavam as mulheres a abortarem: "a prática criminosa do aborto é recurso dos malfadados da profissão, que dela se valem como garantia de subsistência". (MAGALHÃES, 1925, p. 104).

Este médico compõe uma narrativa em que se misturam as visões da medicina e da justiça. No decorrer de seu trabalho verificamos várias vezes a citação do Código 
Penal, bem como a ineficiência do mesmo diploma legal em se tratando de aborto criminoso. Há trechos em que o médico afirma que as leis que deveriam punir o aborto são insuficientes e quase que de todo inúteis: "é defeituosa, além de ineficiente, a repressão legal ao aborto", ou ainda "do Código Penal, o aborto é o único crime que o criminoso divulga com todo o garbo [...] Em todo crime há segredo, negativa e depois dirimente; no do aborto, não: há satisfação e lucro". (MAGALHÃES, 1925, p. 104). Se em todo crime os criminosos devem se esconder, pois serão denunciados e punidos, o aborto se mostrava como uma exceção à regra.

É certo que as mulheres envolvidas em práticas de abortos criminosos não alardeavam aos quatro ventos seu feito, porém não havia um sigilo absoluto em se tratando desta prática. Talvez essas mulheres não considerassem o aborto um crime, mas sim a única opção. Então, o direito penal respondeu: é considerado crime aquilo que é condenado pela sociedade, que vai contra os costumes de uma nação. Tomemos, então, por base uma pesquisa feita pelo próprio Dr. Fernando em seu consultório: " acrescentei que numa pequena estatística, coletando 4.000 fichas de consultório, noto a confissão de mais de $70 \%$ das mulheres que se fazem abortar por motivos inferiores". (MAGALHÃES, 1925, p. 106).

Se um número expressivo de mulheres, desde os anos vinte do século passado, confessaram as práticas de intencional do aborto, então não podemos dizer que para esta população feminina o aborto ia contra os costumes, ao contrário, este 'delito' era bastante recorrente entre as mulheres.

Todavia o conhecimento médico aliou-se ao discurso jurídico na tentativa de policiar e condenar o aborto provocado sem o motivo terapêutico. Os médicos argumentavam que 'as mulheres desabusadas' proclamavam um pretendido direito sobre o corpo, querendo para isso dispor livremente de seus ventres e somente aceitar a maternidade no momento em que achassem conveniente.

Desta maneira, o discurso médico procurou condenar os doutores e os leigos que praticavam abortos, assim como alertar a sociedade e as autoridades judiciais para a necessidade de vigilância sobre o corpo e as práticas femininas, principalmente durante a gestação. Seja para evitar a loucura puerperal e o infanticídio, seja para coibir a interrupção da gravidez, os médicos e a justiça deveriam estar atentos e trabalhando em comum acordo para que as mulheres por 'motivos inferiores' não se privassem de sua função social, gerar e cuidar dos filhos. O 'crime biológico' e antinatural das mulheres era visto durante o início do século XX como um crime contra o Estado, contra o crescimento da Nação e contra o fortalecimento da espécie.

Assim, a vigilância sobre a maternidade, mesmo que muito falha, vai tomando corpo por meio da sua normatização. Essa preocupação com a maternidade, que teria como fim evitar os casos de abortos foi concretizada na tentativa de punição às mulheres desviantes que se envolveram nos 'delitos contra o amor materno'. Neste sentido, a justiça tentou incriminar e punir as mulheres que se negaram a serem mães. Os inquéritos e processos criminais instaurados em diversas comarcas demonstram que o Estado, com o auxílio da medicina, ameaçava de prisão todas aquelas que cometessem o aborto.

\section{Estudo de Caso: Lígia, Morta pelo Aborto}

Ao analisar os caso que ficaram registrados nas comarcas de Castro e Ponta Grossa (PR) sobre as práticas de aborto, percebe-se que essas mulheres, pobres, na totalidade dos casos arrolados em tribunais das cidades mencionadas, narram suas 
histórias de amor e posteriormente as práticas de aborto sob uma lógica que lhes é própria. Relatando suas dificuldades para sobreviver, as difíceis situações para conseguir e manter o emprego, o pouco estudo, a falta de auxílio durante a gestação e as artimanhas femininas como chás e remédios receitados pelas parteiras e até por amigas para interromper a gestação.

Assim sabe-se que as mulheres envolvidas em tramas judiciais vinculadas a sexualidade se caracterizavam por uma situação específica de necessidades físicas, materiais e emocionais, que configuravam a particularidade e a historicidade de suas ações. (ESTEVES, 1989).

A gravidez não planejada e não desejada fez com que essas mulheres pobres se colocassem diante de uma situação-limite que se transformou em casos públicos no judiciário. Como muitas delas eram migrantes procuraram ajuda não nos membros da família, mas sim em conhecidas ou vizinhas. Essas compunham uma espécie de 'rede feminina' que as gestantes julgaram poder contar.

Segundo Baechler (1995) a expressão 'rede' designa todo o conjunto de laços formados entre os indivíduos e não apenas o conjunto de pessoas com as quais os indivíduos estão em contato. No entanto, devido a extensão e amplitude de tais redes os historiadores encontram dificuldades para analisá-las em sua totalidade. Este tipo de relação entre atores sociais cuja variedade e densidade podem oscilar dependendo do parentesco, da vizinhança, da classe e do mercado de trabalho, pressupõe que existam laços estabelecidos nos quais se encontra um vínculo que em diferentes graus de difícil qualificação estabelece ligações de intimidade, reciprocidade e proteção, podendo ser formadas de indivíduos para indivíduos ou de grupos para grupos. (BAECHLER, 1995). Os arranjos e rearranjos destas redes podem variar de acordo com o ciclo de vida dos indivíduos, pois se observa uma presença mais marcante de amigos durante a juventude, de colegas durante a idade madura e dos parentes durante a velhice.

De acordo com Baechler (1995), as redes de sociabilidades são fortemente influenciadas pelas relações tradicionais de gênero, ou seja, cabem às mulheres em primeiro lugar as relações com os mais próximos, como parentes e vizinhos. Entretanto, o autor ressalva que entre as camadas populares as mulheres são lançadas no mercado de trabalho mais cedo o que acarreta em uma diversificação maior de suas redes de interdependências.

Estes vínculos podem ser fortes ou fracos. As relações mais duradouras pressupõem uma ligação mais forte, acarretando em uma intensidade maior nas emoções que despertam assim como na intimidade estabelecida entre os participantes da rede. Quanto mais intensos forem esses laços mais essa rede tende a fechar-se sobre si mesma e a afastar-se de outras redes em uma espécie de 'enquistamento social'.

Ao migrarem, as mulheres rompiam, ao menos parcialmente, com as redes de sociabilidades e proteção social que haviam sido consolidadas nas suas cidades de origens. Este fato pode ter influenciado para a denúncia de muitas delas, pois não contavam com redes sólidas de proteção para esconder suas práticas e deste modo os casos vieram a público. As mulheres indiciadas podem ser percebidas, conforme Baechler, como uma espécie de estrangeiras no sentido amplo da palavra. "O estrangeiro combina a proximidade com o afastamento, na medida em que, vindo de outra parte com seus traços culturais próprios, fixou-se em um determinado lugar, o que o torna elemento do grupo [...]". (BAECHLER, 1995, p. 78). Porém, ao mesmo tempo em que o 
estrangeiro vincula-se a um determinado grupo, mantém com este uma relação que associa exclusão e distância. As relações com os 'estrangeiros' são mais abstratas devido ao fato de possuírem elementos culturais distintos das populações nativas. Assim, partilha-se com os estrangeiros instalações profissionais ou sociais, mas em última instância o que liga o nativo ao estrangeiro é o simples fato de serem seres humanos, nada além disso. Dentro desta perspectiva o que fica evidente no estrangeiro não são as semelhanças, mas sim as diferenças de seus costumes e hábitos, "não é a diferença individual, mas a do país, das cidades, da raça [...]. Basta que este tipo esteja marcado [...], por traços negativos, para que todas as perseguições coletivas se tornem possíveis". (BAECHLER, 1995, p. 79).

Partindo-se dessas considerações, as mulheres processadas pelas práticas de aborto e infanticídio, sendo em sua maioria 'estrangeiras' nas cidades aonde cometeram o crime, não possuíam vínculos e redes fortes de amizades, o que não significa que estas não existiam e sim que eram superficiais, frágeis. Este fato pode ser percebido principalmente nos casos de aborto que geralmente contavam com a ajuda de uma amiga ou mesmo de uma parteira conhecida. As amigas que se tornaram testemunhas nos autos criminais revelam que acompanhavam as gestantes ou mesmo indicavam remédios para fazer 'vir às regras', mas no momento em que o ato do aborto é descoberto elas passam a ser testemunhas de acusação e fontes preciosas para o poder judiciário, pois faziam parte do convívio íntimo da ré e deste modo poderiam prestar informações relevantes não apenas sobre a prática criminosa como também sobre a vida sexual-afetiva da denunciada. Deste modo, seriam capazes de auxiliar na caracterização do dito 'desregramento sexual' que resultou na gravidez indesejada e posteriormente na situação-limite de aborto. Essa afirmação pode ser verificada no processo que narra a história de aborto de Lídia, que resultou na morte da mesma:

[...] a declarante era vizinha de dona Lídia, que no dia 11 do mês de julho de 1965 a declarante encontrava-se em sua residência lavando roupa quando ali chegou sua vizinha, dona Lídia, a qual foi pedir para a declarante a acompanhar até a casa de dona Cecília C., parteira residente na Vila da Palmeirinha. A declarante achou Lídia bastante pálida, porém sabendo que a mesma tinha tomado umas pauladas na cabeça desferida por outros vizinhos, a declarante supôs que era proveniente dos ferimentos recebidos naquela ocasião $[\ldots]$.

Floriana (amiga da gestante Lídia) concordou em acompanhá-la até a casa da referida parteira e, no caminho, Lídia lhe contou que estava grávida de dois meses e ia tentar 'tirar a criança'. Chegando à casa da aludida parteira a amiga contou que Lídia e Cecília entraram em um quarto demorando em torno de meia hora. Posteriormente Lídia contou para Floriana que a parteira Cecília havia colocado uma sonda em seu útero para fazer $\mathrm{o}$ aborto e então as duas amigas voltaram para casa.

A partir deste momento, Floriana procurou, em seu depoimento, demonstrar que não havia se envolvido com as complicações do aborto que resultaram na morte de Lídia e deste modo culpar exclusivamente a parteira e o marido de Lídia pela tragédia:

[...] tendo a declarante ficado em sua residência e dona Lídia ido para a casa; que no sábado a noite a declarante veio a saber que dona Lídia havia falecido no hospital não sabendo qual a causa da morte da mesma (...) que é 
conhecimento de todos que Lídia havia escrito o nome de uma injeção para aborto 'promusol forte' em um papel e dado para seu marido comprar [...].

Percebe-se, assim, que os vínculos de solidariedade entre essas mulheres eram frágeis. Em seu depoimento Floriana admite que não queria se envolver muito no caso de aborto mesmo sendo amiga de Lídia, apenas acompanhou aquela mas não viu a situação posterior, o momento do aborto, e tampouco prestou auxílio quando a amiga foi para o hospital.

Por ser uma mulher casada e, portanto, 'honesta', esta gestante contava com uma rede de amizades que julgava poder acionar no momento da tentativa de eliminar a gestação. A própria informação sobre quem seria a parteira da Vila Palmeirinha que fazia abortos surgiu destas redes femininas de auxílio para a solução de um problema imediato, uma criança indesejada em uma família pobre que já contava com outros filhos. Porém, estas redes de sociabilidades e de socialização de conhecimentos a respeito de evitar crianças não se mostraram sólidas, principalmente quando envolvia a participação de um agente externo, o poder judiciário. Neste ponto as denunciadas ficavam sozinhas uma vez que os vizinhos e amigos se tornavam parte do processo como testemunhas de acusação.

Pobres, sem nenhum auxílio do Estado e sendo parte integrante de redes de auxílio duvidosas, estas mulheres se tornaram presas fáceis para o judiciário. Mesmo tendo estabelecido redes de convivências vicinais essas mulheres não estavam protegidas.

Outro ponto que merece destaque quando analisamos o aborto é que esses casos envolvem questões relativas à honra, à sexualidade e questionam o mito do amor materno. Deste modo, não são casos de fácil solução para o Poder Judiciário, porém, ao se tornar pública uma denúncia de aborto, as mulheres e sua vida afetivo-sexual são lançadas em um novo cenário, no palco do judiciário. Neste novo local, os casos eram reconstituídos pelas partes envolvidas de diferentes maneiras e materializadas em forma de autos. Por meio dos depoimentos dos vários envolvidos como acusadas, testemunhas, peritos e advogados, pudemos perceber as múltiplas construções das narrativas que cada um elaborou. Assim, esses atores sociais empenharam-se por relatar a parte do real que mais acreditassem ou que julgassem ser a mais conveniente e deste modo surgiam as variadas versões sobre o mesmo fato. Nesta perceptiva, podemos entender o processo criminal como uma 'inversão' ou uma reconstrução ficcional de cada parte do social envolvida nele, como observa Mariza Corrêa:

No momento em que os atos se transformam em autos, os fatos em versões, o concreto perde quase toda a sua importância e o debate se dá entre atores do jurídico, cada um deles usando a parte do "real" que melhor reforce o seu ponto de vista. Nesse sentido é o real que é processado, moído e remoído até que se possa extrair dele um esquema elementar sobre o qual se construirá um modelo de culpa e um modelo de inocência. (CORREA,1983, p. 67).

As argumentações de culpa ou de inocência eram construídas por um conjunto de interesses, individuais e coletivos, que cada parte possuía. Esses modelos foram reforçados e de certa forma determinados por meio de inúmeras normas sociais que se referiam tanto a pena que a infração poderia proporcionar, como a cobrança de normas de comportamento para os sexos. (FAUSTO, 1984). Deste modo a avaliação dos modelos de conduta dos indivíduos envolvidos nas ações penais foram fixados, tendo como pressuposto características de gênero, de papéis sociais, de idade e até mesmo de 
posição social. Essas variáveis não eram tratadas pelo judiciário como meras qualificações para as envolvidas em casos de aborto, mas tornaram-se elementos do próprio processo penal, concorrendo de modo igual para o julgamento, penal ou moral, das indiciadas e assim poderiam auxiliar ou mesmo justificar as sentenças ou a ausência de desfecho para o processo criminal.

Acreditamos que as ações penais e, portanto, as falas e argumentações ali encontradas, foram elaboradas buscando seguir normas de comportamentos, modelos de condutas sociais que foram, conforme demonstrou Norbert Elias (1990), sendo construídas, elaboradas e fixadas ao longo da história de modo a ditar padrões de normalidades. A incorporação, por vezes morosa, dessas normas de condutas individuais e coletivas acabaram por resultar na formação de uma rede de comportamentos que exerceu influência na elaboração das legislações, uma vez que parte significativa do Direito está baseada nos costumes e padrões aceitos socialmente e, deste modo, este campo de referências sociais construído historicamente acabou por influenciar de maneira decisiva nas falas e saberes encontrados nos processos penais de aborto.

Os indivíduos estariam envolvidos e sujeitos a normas de controle e modelações uma vez que permaneceriam inseridos na vida social, ou seja, em suas relações com os demais seres humanos. Todavia um elemento relevante para ser analisado neste ponto é a localização social das indiciadas nos casos de abortos. O espaço ocupado por essas mulheres nas tramas das relações sociais de interdependências foi determinante para analisarmos as suas histórias; assim como a construção feita pelos saberes médicos e jurídicos sobre estas práticas e sobre as envolvidas e denunciadas pelas ações de aborto.

Este tipo de ação penal envolve fatores que extrapolam a materialidade e comprovação da autoria do crime. Muito além desses elementos, os processos de aborto são carregados de valores subjetivos, como manutenção da honra, comportamento moral e obrigação do instinto materno. Deste modo, a justiça acreditava na necessidade da investigação o mais completa possível da vida das indiciadas. Era necessário colocá-las em seu lugar na sociedade para, a partir daí, construir elementos de culpa ou não, ou seja, para então justificar e perdoar ou punir àquelas que renunciaram, em algum momento da vida, à maternidade. Assim, o campo de investigação jurídico-policial se estende para além da cena e do contexto do crime. Buscava-se reconstruir e, ao mesmo tempo, avaliar e qualificar a biografia individual de cada protagonista nas cenas de aborto, trazendo desta maneira para compor os processos, os hábitos, temperamentos, comportamentos, vida pregressa e até mesmo a vida sexual dessas mulheres. Elas deveriam ter seus corpos e suas vidas analisados na busca de indícios e provas que pudessem condená-las ou inocentá-las. Enfim, em busca de elementos que as enquadrassem em um campo de comportamentos sociais e tendo como referência o campo em que foram enquadradas, o judiciário as sentenciaria.

\section{Considerações Finais}

A documentação penal encontrada em Castro e Ponta Grossa (PR) referente a aborto é extremamente fragmentada, pois os processos não apresentam todos os dados das envolvidas e geralmente trazem poucos depoimentos, além disso, poucas vezes chegam a gerar pareceres de advogados, promotores ou juízes, pois foram arquivados por falta de provas. As práticas de absolvição, arquivamento ou prescrição foram uma constante na jurisprudência das cidades de Castro e Ponta Grossa (PR). 
Esses casos ficaram registrados parcialmente para a justiça, são histórias que na narrativa daqueles processos jamais terão um ponto final. Estas mulheres foram absolvidas ou esquecidas pelo olhar sempre vigilante da justiça.

Essa constatação nos levou ao questionamento de como um discurso jurídico implacável que caracterizava as indiciadas como monstros cruéis, mulheres feras e sem alma, pode propiciar condições para que o Tribunal de Júri as absolvessem? Como interpretar a grande maioria dos casos que prescreveram, casos sem solução e que depois de certo tempo foram arquivados? Como explicar este paradoxo? Qual o motivo que transforma a 'mulher-monstro' em mulher-perdoada?

Acreditamos que apesar da maternidade ser considerada um tema sagrado e o amor materno ser cobrado das mulheres como condição fundamental para o equilíbrio emocional e mesmo o regramento da sexualidade, em casos que envolviam o aborto e a justiça estabeleciam um equilíbrio entre as noções de 'regra' e a 'estratégia'.

A regra era apresentada por meio dos discursos repressores que condenavam com duras palavras aquelas que em determinado momento da vida se recusaram a ser mães. Era cobrada das mulheres, no plano da regra, a condição de assumir a criança desde o início da gestação, assumir e reconhecer-se enquanto grávida, valorizando o instinto materno que deveria superar todas as dificuldades emocionais e financeiras que as gestantes enfrentavam. Pela regra, elas deveriam tornar público o seu estado de gestante como uma espécie de obrigação moral, uma vez que o amor materno deveria falar mais alto. Deste modo, a princípio e como regra, todos condenavam as práticas de aborto e infanticídio e as mulheres que foram protagonistas destas cenas. Muitos esperavam que elas pagassem pelo que fizeram, pois assumir um filho era o dever das mães. Assim, no nível do discurso, essas mulheres foram duramente condenadas, taxadas de 'loucas', 'burras', cruéis, 'coração de tigre', esquisitas, perversas e 'monstros'. Porém, o perdão e a compaixão foram os desfechos dos casos.

Este fato pode ser explicado pela 'estratégia'. Não um recurso usado apenas pelo aparelho jurídico-penal ou médico-legal, mas sim uma estratégia amplamente utilizada por toda a sociedade. Por meio dessa tática social verificamos que no desenrolar dos fatos foram levadas em consideração as condições emocionais e de vida material das indiciadas, de modo a ponderar que elas estavam passando por uma 'situação-limite'. Pobres, sem grandes estudos escolares, sozinhas, com empregos mal remunerados e, muitas vezes, morando de favor na casa dos patrões elas optaram ou foram levadas pelo desespero e acabaram realizando crimes contra a maternidade.

Com o triunfo da estratégia do perdão se demonstrou que o que realmente estava em jogo e o que estava socialmente sendo julgado não era a morte de uma criança ou de um feto, mas sim se as gestantes deveriam ou não assumir o filho diante das situações tão adversas de suas vidas. Este resultado demonstra que a negação da maternidade era condenada no plano da regra, mas em algumas circunstâncias, era perdoado e até esquecido nos arquivos empoeirados da justiça.

1 Para efeito de citação a grafia original de todas as documentações apresentadas neste artigo foram mantidas.

2 Trata-se da maternidade Pró-Mater, fundada o Rio de Janeiro (RJ), em 1918. Teve entre seus médicos Fernando de Magalhães, considerado 'o pai' 
da obstetrícia no Brasil.

\section{Referências}

BAECHLER, Jean. Grupos e sociabilidade. In: BOUDON, Raymond (org). Tratado de Sociologia. Rio de Janeiro: Jorge Zahar, 1995, p. $65-107$.

BRASIL. Secção III. Código Criminal do Império do Brazil. Lei de 16 de dezembro de 1830. Dezembro de 1830.

BRASIL. Decreto n. 847 de 11 de outubro de 1890. Dispões sobre o aborto, artigos: 300, 301 e 302. Outubro de 1890.

CARVALHO, Odetto. A ignorância materna e a condicção do nascituro. 1926. Tese (Doutorado em Medicina) - Faculdade de Medicina do Rio de Janeiro, Rio de Janeiro, Rio de Janeiro.

CORREAA, Mariza. Morte em família. Rio de Janeiro: Graal, 1983.

CUNHA, Francisco C. Carneiro. Do abortamento. 1905. Tese (Doutorado em Obstetrícia) - Faculdade de Medicina da Bahia, Bahia.

ELIAS, Norbert. O processo civilizador. Volume II. Rio de Janeiro: Zahar, 1990.

ESTEVES, Martha de Abreu. Meninas Perdidas: os populares e o cotidiano do amor no Rio de Janeiro da Belle Époque. Rio de Janeiro: Paz e Terra, 1989.

FAUSTO, Boris. Crime e cotidiano: A criminalidade em São Paulo (1880-1924). São Paulo: Brasiliense, 1984.

FERREIRA, Arthur L. Da gravidez e sua Higiene. 1907 (doutorado em Ginecologia e Obstetrícia) - Faculdade de Medicina da Bahia, Bahia.
HUNGRIA, Nelson. Código Penal Comentado. São Paulo: Forense, 1956.

MAGALHÃES, Fernando. Obstetrícia Forense. Rio de Janeiro: Guanabara Waissman-koogan ltda, 1925.

MCLAREN, Angus. História da Contracepção: da antiguidade à actualidade. 1 ed. Lisboa: Terramar, 1990.

MORAES, Leôncio Gomes Pereira. Do aborto provocado. 1873. Tese (Doutorado em Medicina) - Faculdade de Medicina do Rio de Janeiro, Rio de Janeiro, Rio de Janeiro.

NACUR, Jean-Yves; VALENT, Catherine. Histoire de l'Avortement. Paris: Éditions du Seuil, 2003.

PEDRO, Joana Maria. Práticas Proibidas: Práticas Costumeiras de aborto e infanticídio no século XX. Florianópolis: Cidade Futura, 2003.

PRADO, Dando. O que é aborto. Coleção primeiros Passos: Brasiliense, 1985.

Recebido em 18 de dezembro de 2013.

Aceito em 12 de fevereiro de 2014. 